\title{
A Meta-Analysis of Slow Pull versus Suction for Endoscopic Ultrasound-Guided Tissue Acquisition
}

\author{
Yousuke Nakai ${ }^{1,2}$, Tsuyoshi Hamada ${ }^{1}$, Ryunosuke Hakuta ${ }^{1,2}$, Tatsuya Sato ${ }^{1}, K^{2}$ Kazunaga Ishigaki ${ }^{1}$, Kei Saito $^{1}$, \\ Tomotaka Saito ${ }^{1}$, Naminatsu Takahara ${ }^{1}$, Suguru Mizuno ${ }^{1}$, Hirofumi Kogure ${ }^{1}$, and Kazuhiko Koike ${ }^{1}$ \\ Departments of ${ }^{1}$ Gastroenterology and ${ }^{2}$ Endoscopy and Endoscopic Surgery, Graduate School of Medicine, The University of Tokyo, \\ Tokyo, Japan
}

\author{
Article Info \\ Received August 18, 2020 \\ Revised October 29, 2020 \\ Accepted November 3, 2020 \\ Published online February 19, 2021 \\ Corresponding Author \\ Yousuke Nakai \\ ORCID https://orcid.org/0000-0001-7411-1385 \\ E-mail ynakai-tky@umin.ac.jp
}

Background/Aims: Endoscopic ultrasound (EUS)-guided tissue acquisition is widely utilized as a diagnostic modality for intra-abdominal masses, but there remains debate regarding which suction technique, slow pull (SP) or conventional suction (CS), is better. A meta-analysis of reported studies was conducted to compare the diagnostic yields of SP and CS during EUS-guided tissue acquisition.

Methods: We conducted a systematic electronic search using MEDLINE/PubMed, Web of Science, and the Cochrane Central Register of Controlled Trials to identify clinical studies comparing SP and CS. We meta-analyzed accuracy, sensitivity, blood contamination and cellularity using the random-effects model.

Results: A total of 17 studies (seven randomized controlled trials, four prospective studies, and six retrospective studies) with 1,616 cases were included in the analysis. Compared to CS, there was a trend toward better accuracy (odds ratio [OR], 1.48; 95\% confidence interval [Cl], 0.97 to $2.27 ; p=0.07)$ and sensitivity $(\mathrm{OR}, 1.67 ; 95 \% \mathrm{Cl}, 0.95$ to $2.93 ; \mathrm{p}=0.08)$ with $\mathrm{SP}$ and a significantly lower rate of blood contamination (OR, $0.48 ; 95 \% \mathrm{Cl}, 0.33$ to $0.69 ; \mathrm{p}<0.01)$. However, there was no significant difference in cellularity between SP and CS, with an OR of $1.28(95 \% \mathrm{Cl}, 0.68$ to $2.40 ; p=0.45)$. When the use of a 25-gauge needle was analyzed, the accuracy and sensitivity of SP were significantly better than those of CS, with ORs of $4.81(95 \% \mathrm{Cl}, 1.99$ to $11.62 ; \mathrm{p}<0.01)$ and $4.69(95 \% \mathrm{Cl}, 1.93$ to $11.40 ; p<0.01)$, respectively.

Conclusions: Compared to CS, SP appears to provide better accuracy and sensitivity in EUSguided tissue acquisition, especially when a 25-gauge needle is used. (Gut Liver 2021;15:625633)

Key Words: Endoscopic ultrasonography; Fine needle aspiration; Slow pull; Suction.

\section{INTRODUCTION}

Endoscopic ultrasound-guided fine needle aspiration (EUS-FNA), first introduced in the early $1990 \mathrm{~s},{ }^{1,2}$ is now established as a safe and reliable technique to obtain the pathological diagnosis of intra-abdominal lesions. One meta-analysis of clinical studies on EUS-FNA showed sensitivity of $85 \%$ and specificity of $98 \%$ in pancreatic solid lesions ${ }^{3}$ but there remains some controversy in EUSFNA procedures such as the needle size, the use of stylet and rapid onsite evaluation. ${ }^{4}$ More recently, EUS-guided fine needle biopsy (EUS-FNB) using newly developed core needles ${ }^{5,6}$ has emerged as a potentially more effective alternative. The application of suction has also been discussed in terms of quality and quantity of tissue acquisition. ${ }^{7}$ While high negative pressure may increase cellularity of the specimen, it can increase blood contamination at the same time. Slow pull (SP), or capillary suction, technique is one of options for application of suction during EUS-FNA or FNB and we previously reported that SP was associated with better tissue acquisition compared to the conventional suction (CS) technique, especially when a 25-gauge FNA 
needle was used. ${ }^{8}$ The usefulness of SP was also reported in a 25-gauge core biopsy needle. ${ }^{9}$ However, there still remains debate on the best technique among options including no suction, slow pull, suction or wet suction ${ }^{10}$ during EUS-guided tissue acquisition. To address this clinical question, we conducted a meta-analysis to compare SP and CS for EUS-guided tissue acquisition of solid lesions.

\section{MATERIALS AND METHODS}

\section{Study selection}

A systematic electronic search using MEDLINE/ PubMed, Web of Science, and the Cochrane Central Register of Controlled Trials was conducted independently by two authors (Y.N. and R.H.). We identified clinical studies comparing SP and CS for EUS-guided tissue acquisition that had been reported until January 2020. The key search words were "endoscopic ultrasonography," "EUS-FNA," "fine needle aspiration," "fine needle biopsy," "slow pull," "capillary" and "suction." We included fully published articles and conference abstracts that had involved $\geq 20$ patients in total and limited the search to English language (Supplementary Fig. 1). Bibliographies of the identified reports were further screened for additional studies. The literature search was last performed on 31 January 2020. Disagreements were resolved through discussion with a second author (T.H.). This study was conducted in compliance with the Preferred Reporting Items for Systematic Reviews and Meta-Analyses statement.

\section{Data collection}

The following data were extracted using a prespecified data extraction form: study design, EUS-guided tissue acquisition characteristics (target lesions, the needle size and type, and suction methods) and EUS-guided tissue acquisition outcomes (accuracy, sensitivity, blood contamination and cellularity). There were no standard evaluation methods for the evaluation of blood contamination and cellularity, and some studies used semiquantitative scores with variations in the definitions. ${ }^{11,12}$ Therefore, these outcome variables were defined according to the original protocol of each study. Furthermore, we also incorporated the presence of a visible or histological core as a substitute for cellularity in some studies if those semiquantitative scores were not available. The quality of the studies included in the analysis was assessed using Cochrane Collaboration Risk of Bias Tool for randomized controlled trials (RCTs) ${ }^{13}$ and Newcastle-Ottawa scale for non-RCTs. ${ }^{14}$

\section{Statistical analyses}

Using the data extracted from the studies identified, summary odds ratios (ORs) of binary outcome variables (i.e., accuracy, sensitivity, blood contamination and cellularity) comparing SP and CS were computed as means of the DerSimonian-Laird random-effects model. ${ }^{15}$ Given potential heterogeneity in study populations and endoscopic procedures between the studies, we utilized the randomeffects model throughout the current study. Statistical heterogeneity between studies was assessed based on the $\mathrm{Q}$ and $\mathrm{I}^{2}$ statistics. ${ }^{16}$ For the $\mathrm{Q}$ statistic, we used a p-value of 0.10 for statistical significance in view of the low power of tests for heterogeneity. ${ }^{17}$ The $\mathrm{I}^{2}$ statistics of around $25 \%$, $50 \%$, and $75 \%$ were considered as suggestive of low-, moderate-, and high-level heterogeneity, respectively. ${ }^{18} \mathrm{We}$ calculated 95\% confidence interval (CI) for each summary

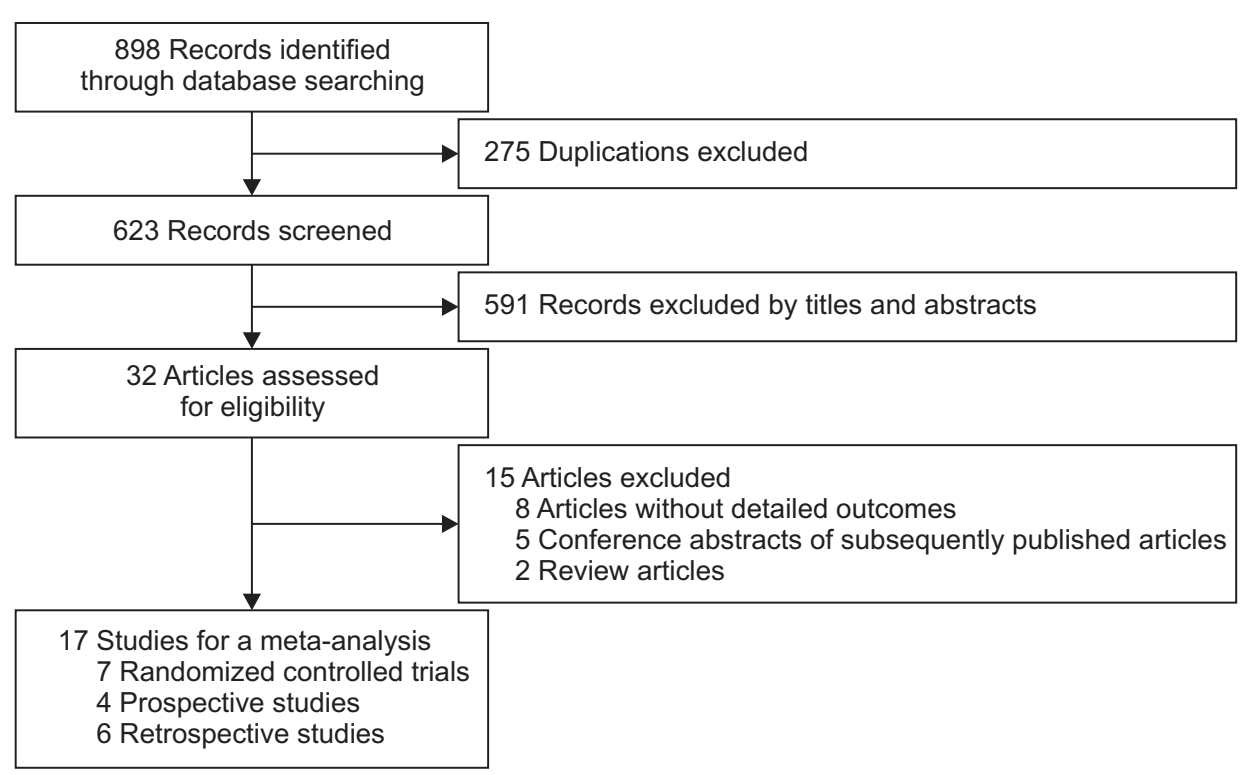

Fig. 1. Flowchart of study selection for the meta-analysis of slow pull versus conventional suction techniques for endoscopic ultrasound-guided tissue acquisition. 


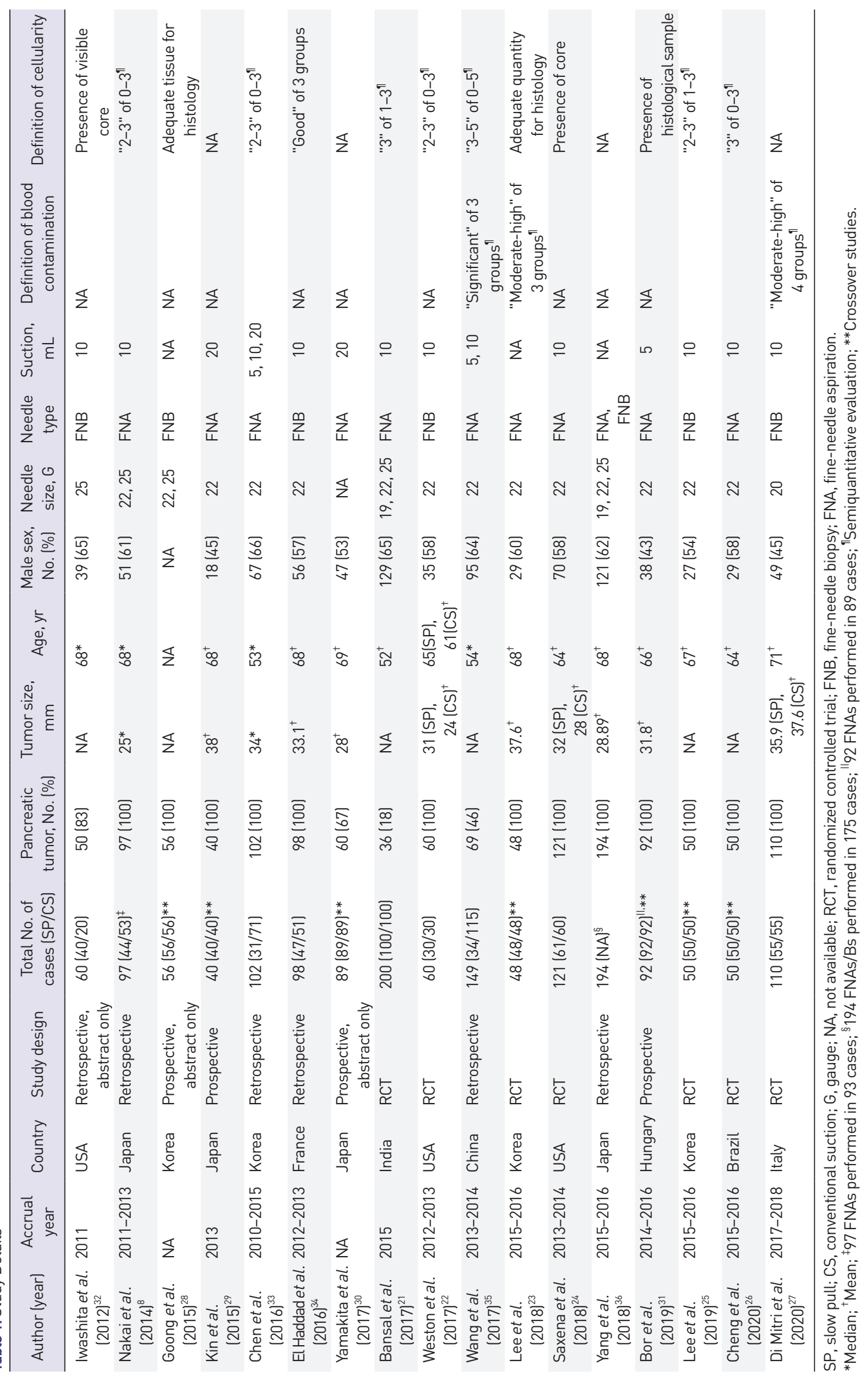


OR. We assessed potential publication bias using the funnel plot with the Begg rank correlation test ${ }^{19}$ and the Egger linear regression test. ${ }^{20}$ We performed subgroup analyses stratified by needle size (22-gauge vs 25 -gauge) and type (FNA vs FNB). Subgroup analysis of studies including pancreatic lesions alone was also performed. In addition, we performed a sensitivity analysis limited to seven RCTs.

A two-sided p-value $<0.05$ was considered statistically significant. All analyses were performed using $\mathrm{R}$ software version 3.6.3 and the meta package ( $\mathrm{R}$ Development Core Team; The R Foundation, Vienna, Austria, http://www.rproject.org).

\section{RESULTS}

\section{Search results}

The initial search identified a total of 898 publications and after screening for eligibility, 17 studies with 1,616 cases were included in the analysis; seven RCTs, ${ }^{21-27}$ four pro-

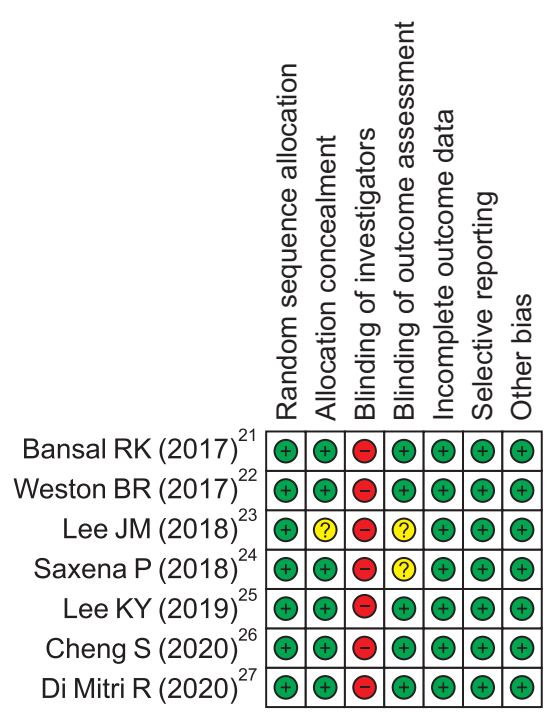

Fig. 2. Risk of bias in randomized controlled trials.

+ , low risk of bias; -, high risk of bias; ?, unclear risk of bias. spective studies, ${ }^{28-31}$ and six retrospective studies ${ }^{8,32-36}$ (Fig. 1). The study characteristics are summarized in Table 1 and the risk of bias is shown in Fig. 2 and Table 2. Thirteen studies included pancreatic lesions alone and four studies included both pancreatic and non-pancreatic lesions. The needle size was 25 -gauge in one, 22-gauge in 10, 20-gauge in one, and various in five studies. The needle type was conventional FNA needles alone in 10, FNB needles alone in six, and both in one. Selection of SP and CS was randomly allocated in seven RCTs and cross-overed in four prospective studies. Among six retrospective studies, three studies were historical cohort comparative studies and no detailed description on selection of SP and CS was available in the remaining three studies.

\section{Accuracy of pathological diagnosis}

The results of our meta-analysis are summarized in Table 3. There was a trend toward better accuracy in SP with OR of 1.48 (95\% CI, 0.97 to 2.27; p=0.07) (Fig. 3A). In an analysis of four RCTs, ${ }^{23-25,27}$ the accuracy of SP was significantly better than that of CS with OR of 1.86 (95\% CI, 1.07 to 3.23; $p=0.03$ ) (Fig. 3B). There was no significant publication bias in ORs for accuracy comparing SP versus $\mathrm{CS}\left(\mathrm{p}_{\text {Begg }}=0.90\right.$ and $\left.\mathrm{p}_{\text {Egger }}=0.88\right)$ (Supplementary Fig. $2 \mathrm{~A}$ ).

Table 2. Risk of Bias in Non-Randomized Controlled Trials

\begin{tabular}{lccc}
\multicolumn{1}{c}{ Author (year) } & Selection & Comparability & Exposure \\
\hline Iwashita et al. $(2012)^{32}$ & $* *$ & $*$ & $* *$ \\
Nakai et al. $(2014)^{8}$ & $* *$ & $*$ & $* * *$ \\
Goong et al. $(2015)^{28}$ & $* *$ & $*$ & $* * *$ \\
Kin et al. $(2015)^{29}$ & $* *$ & $* *$ & $* * *$ \\
Chen et al. $(2016)^{33}$ & $* *$ & $*$ & $* *$ \\
El Haddad et al. (2016) & $* *$ & $*$ & $* *$ \\
Yamakita et al. $(2017)^{30}$ & $*$ & $* *$ & $* *$ \\
Wang et al. $(2017)^{35}$ & $* *$ & $*$ & $* *$ \\
Yang et al. $(2018)^{36}$ & $*$ & $*$ & $*$ \\
Bor et al. $(2019)^{31}$ & $* *$ & $* *$ & $* * *$ \\
\hline
\end{tabular}

Studies were awarded a maximum of 4 stars for selection, 2 stars for comparability, and 3 stars for exposure.

Table 3. Summary Odds Ratios Comparing Slow Pull and Conventional Suction Techniques for EUS-Guided Tissue Acquisition (Overall or by Needle Characteristics)

\begin{tabular}{|c|c|c|c|c|c|c|c|c|}
\hline Studies & $\begin{array}{l}\text { Accuracy } \\
(95 \% \mathrm{CI})\end{array}$ & $\mathrm{p}$-value & $\begin{array}{l}\text { Sensitivity } \\
\text { (95\% CI) }\end{array}$ & $p$-value & $\begin{array}{c}\text { Blood contamination } \\
\qquad(95 \% \mathrm{CI})\end{array}$ & $\mathrm{p}$-value & $\begin{array}{l}\text { Cellularity } \\
\text { (95\% CI) }\end{array}$ & $p$-value \\
\hline Overall & $1.48(0.97-2.27)$ & 0.07 & $1.67(0.95-2.93)$ & 0.08 & $0.48(0.33-0.69)$ & $<0.01$ & $1.28(0.68-2.40)$ & 0.45 \\
\hline $\mathrm{RCT}$ & $1.86(1.07-3.23)$ & 0.03 & $1.39(0.62-3.12)$ & 0.43 & $0.51(0.31-0.83)$ & $<0.01$ & $1.21(0.83-1.75)$ & 0.32 \\
\hline 22-Gauge & $1.63(0.99-2.67)$ & 0.05 & $1.74(0.88-3.45)$ & 0.11 & $0.56(0.31-1.01)$ & 0.05 & $1.18(0.78-1.78)$ & 0.44 \\
\hline 25-Gauge & $4.81(1.99-11.62)$ & $<0.01$ & $4.69(1.93-11.40)$ & $<0.01$ & $0.38(0.07-2.03)$ & 0.26 & $1.35(0.10-18.33)$ & 0.82 \\
\hline FNA & $1.49(0.90-2.49)$ & 0.12 & $1.74(0.88-3.45)$ & 0.15 & $0.43(0.27-0.68)$ & $<0.01$ & $0.85(0.53-1.34)$ & 0.48 \\
\hline FNB & $1.49(0.59-3.79)$ & 0.40 & $1.17(0.26-5.29)$ & 0.84 & $0.65(0.36-1.20)$ & 0.17 & $2.59(0.84-8.05)$ & 0.10 \\
\hline Pancreas & $1.54(1.02-2.32)$ & 0.04 & $1.51(0.85-2.68)$ & 0.16 & $0.56(0.38-0.81)$ & $<0.01$ & $1.19(0.71-1.99)$ & 0.51 \\
\hline
\end{tabular}

EUS, endoscopic ultrasound; $\mathrm{Cl}$, confidence interval; RCT, randomized controlled trial; FNA, fine-needle aspiration; FNB, fine-needle biopsy. 


\section{Sensitivity}

Sensitivity was evaluated in nine studies. Similar to the analysis of accuracy, there was a trend toward a better sensitivity in SP with OR of 1.67 (95\% CI, 0.95 to $2.93 ; \mathrm{p}=0.08$ ) (Fig. 3C). In the analysis of four RCTs, ${ }^{22-24,27}$ however, there was no significant difference in sensitivity between $\mathrm{SP}$ and CS with OR of 1.39 ( $95 \%$ CI, 0.62 to 3.12; $\mathrm{p}=0.43$ ). There was no significant publication bias in ORs for sensitivity comparing SP versus CS ( $\mathrm{p}_{\text {Begg }}=0.40$ and $\left.\mathrm{p}_{\mathrm{Egger}}=0.92\right)$ (Supplementary Fig. 2B).

\begin{tabular}{lrrrr} 
A & \multicolumn{3}{c}{ Slow pull } & \multicolumn{3}{c}{ Suction } \\
Events & Total & Events & Total \\
Study & 38 & 40 & 15 & 20 \\
Iwashita T $(2012)^{32}$ & 156 & 186 & 136 & 181 \\
Nakai Y $(2014)^{8}$ & 45 & 56 & 46 & 56 \\
Goong HJ $(2015)^{28}$ & 36 & 40 & 36 & 40 \\
Kin T $(2015)^{29}$ & 28 & 31 & 42 & 71 \\
Chen JY $(2016)^{33}$ & 71 & 89 & 77 & 89 \\
Yamakita K $(2017)^{30}$ & 42 & 48 & 34 & 48 \\
Lee JM $(2018)^{23}$ & 49 & 61 & 42 & 60 \\
Saxena P $(2018)^{24}$ & 67 & 92 & 70 & 92 \\
Bor R $(2019)^{31}$ & 45 & 50 & 40 & 50 \\
Lee KY $(2019)^{25}$ & 51 & 55 & 53 & 55 \\
Di Mitri R $(2020)^{27}$ & & & & \\
& & 748 & & 762 \\
Random effects model & & & &
\end{tabular}

B

Study

Lee JM (2018) ${ }^{23}$

Saxena $\mathrm{P}(2018)^{24}$

Lee KY (2019)

Di Mitri R (2020)

Random effects model

Heterogeneity: $I^{2}=3 \%, p=0.38$

\begin{tabular}{rrrr}
\multicolumn{2}{c}{ Slow pull } & \multicolumn{2}{c}{ Suction } \\
Events & Total & Events & Total \\
42 & 48 & 34 & 48 \\
49 & 61 & 42 & 60 \\
45 & 50 & 40 & 50 \\
51 & 55 & 53 & 55 \\
& & & \\
& 214 & & 213
\end{tabular}

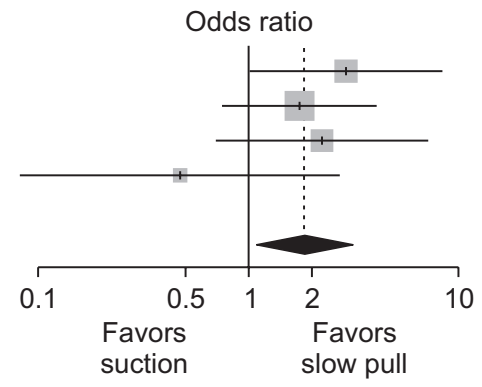

OR

$95 \% \mathrm{Cl}$

2.88

1.75

$[1.00 ; 8.30]$

$[0.76 ; 4.05]$

$[0.71 ; 7.14]$

$0.48 \quad[0.08 ; 2.74]$

1.86
$[1.07 ; 3.23]$
$p=0.03$

Weight

$26.5 \%$

$41.2 \%$

$22.3 \%$

$10.0 \%$

$100.0 \%$
C

Study

\begin{tabular}{rrrr}
\multicolumn{2}{c}{ Slow pull } & \multicolumn{2}{c}{ Suction } \\
Events & Total & Events & Total \\
37 & 39 & 15 & 20 \\
141 & 171 & 115 & 160 \\
34 & 38 & 35 & 38 \\
15 & 17 & 17 & 43 \\
14 & 22 & 15 & 20 \\
34 & 40 & 26 & 40 \\
45 & 55 & 38 & 55 \\
18 & 23 & 133 & 158 \\
50 & 54 & 48 & 50 \\
& & & \\
& 459 & & 584
\end{tabular}

Random effects model Heterogeneity: $I^{2}=53 \%, p=0.03$

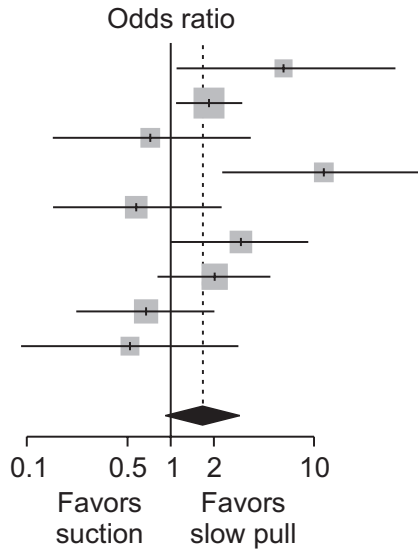

$\begin{array}{rrr}\text { OR } & 95 \% \text { Cl } & \text { Weight } \\ 6.17 & {[1.08 ; 35.35]} & 7.2 \% \\ 1.84 & {[1.09 ; 3.10]} & 19.3 \% \\ 0.73 & {[0.15 ; 3.50]} & 8.3 \% \\ 11.47 & {[2.32 ; 56.65]} & 8.1 \% \\ 0.58 & {[0.15 ; 2.21]} & 10.1 \% \\ 3.05 & {[1.03 ; 9.02]} & 12.5 \% \\ 2.01 & {[0.82 ; 4.91]} & 14.7 \% \\ 0.68 & {[0.23 ; 1.99]} & 12.6 \% \\ 0.52 & {[0.09 ; 2.98]} & 7.2 \% \\ & & \\ 1.67 & {[0.95 ; 2.93]} & 100.0 \% \\ & p=0.08 & \end{array}$

Fig. 3. Comparison of the results of pathological diagnoses between slow pull and conventional suction techniques. (A) Accuracy (overall). (B) Accuracy (randomized controlled trials). (C) Sensitivity loverall). The odds ratio (OR) (center of the gray square) for slow pull compared with conventional suction techniques is presented for each study along with its $95 \%$ confidence interval ( $\mathrm{Cl}$; horizontal line). The summary OR based on the meta-analysis via the random-effects model is presented at the bottom of each panel (center of the black diamond) along with its $95 \% \mathrm{Cl}$ (width of the black diamond). The $\mathrm{p}$-value for the $\mathrm{Q}$-statistic for between-study heterogeneity is shown. 


\section{Blood contamination and cellularity}

In an analysis of eight studies with available data on blood contamination, SP was associated with a significantly lower rate of blood contamination compared to CS with OR of 0.48 (95\% CI, 0.33 to 0.69 ; p $<0.01$ ) (Fig. 4A). The analysis of five RCTs ${ }^{21,23,25-27}$ revealed similar results with OR of 0.51 ( $95 \%$ CI, 0.31 to 0.83 ; $\mathrm{p}<0.01$ ). There was no significant publication bias in ORs for blood contamination comparing SP versus CS ( $\mathrm{p}_{\text {Begg }}=0.32$ and $\left.\mathrm{p}_{\text {Egger }}=0.24\right)$ (Supplementary Fig. 2C). In an analysis of 13 studies with available data on cellularity, there was no significant difference between SP and CS with OR of $1.28(\mathrm{p}=0.45)$ (Fig. 4B). This null finding was consistently observed in an analysis of six RCTs (OR, 1.21; 95\% CI, 0.83 to 1.75 ; $\mathrm{p}=0.32){ }^{21-27}$ There was no significant publication bias in ORs for cellularity comparing SP versus CS ( $\mathrm{p}_{\text {Begg }}=0.54$ and $\left.p_{\text {Egger }}=0.72\right)$ (Supplementary Fig. 2D).

\section{Subgroup analyses by needle size or type}

We performed exploratory analyses stratified by needle size or type to identify any subgroup with different outcomes by SP versus CS (Table 3). In an analysis of EUSFNA or -FNB using a 22-gauge needle, ORs of accuracy, sensitivity, blood contamination and cellularity were 1.63 $(\mathrm{p}=0.05), 1.74(\mathrm{p}=0.11), 0.56(\mathrm{p}=0.05)$ and $1.18(\mathrm{p}=0.44)$. When a 25-gauge needle was analyzed, ORs of accuracy, sensitivity, blood contamination and cellularity were 4.81 $(\mathrm{p}<0.01), 4.69(\mathrm{p}<0.01), 0.38(\mathrm{p}=0.26)$ and $1.35(\mathrm{p}=0.82)$. The subgroup analyses of EUS-FNA and EUS-FNB were also performed. When FNA needles were analyzed, ORs of accuracy, sensitivity, blood contamination and cellularity were $1.49(\mathrm{p}=0.12), 1.74(\mathrm{p}=0.15), 0.43(\mathrm{p}<0.01)$ and 0.85
A

Study

Nakai Y (2014) ${ }^{8}$

Chen JY $(2016)^{33}$

Bansal RK $(2017)^{21}$

Wang R (2017)

Lee JM (2018)

Lee KY (2019)

Cheng S (2020) ${ }^{26}$

Di Mitri R (2020) ${ }^{27}$

Random effects model

Heterogeneity: $I^{2}=43 \%, p=0.09$

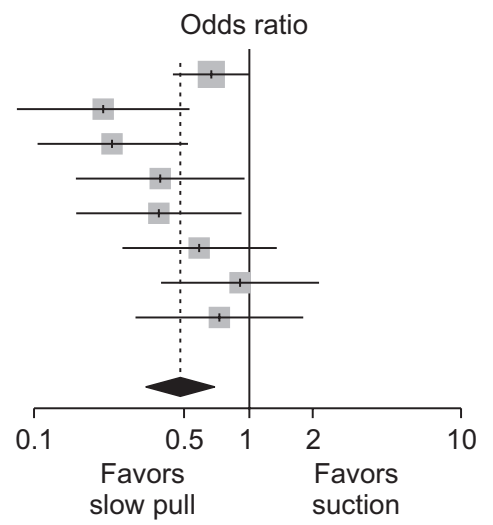

OR
0.67
0.21
0.23
0.39
0.38
0.59
0.91
0.73
0.48

$95 \% \mathrm{C}$

[0.45; 1.02]

$[0.08 ; 0.52]$

$[0.10 ; 0.52]$

$[0.16 ; 0.97]$

$[0.16 ; 0.92]$

$[0.26 ; 1.35]$

[0.39; 2.12]

[0.30; 1.80]

[0.33; 0.69]

$p<0.01$
Weight

$21.7 \%$

$10.4 \%$

$12.2 \%$

$10.5 \%$

$11.0 \%$

$11.9 \%$

$11.5 \%$

$10.7 \%$

$100.0 \%$

\section{B}

\section{Study}

Iwashita T (2012)

Nakai Y (2014) ${ }^{8}$

Goong HJ (2015)

Chen JY (2016)

El Haddad R (2016) ${ }^{34}$

Bansal RK (2017)

Weston BR (2017) 22

Wang R $(2017)^{35}$
Lee JM (2018)

Saxena $P(2018)^{24}$

Bor R $(2019)^{31}$

Lee KY $(2019)^{25}$

Cheng $S(2020)^{26}$

Random effects model

Heterogeneity: $I^{2}=87 \%, p<0.01$

\begin{tabular}{rrrr}
\multicolumn{2}{c}{ Slow pull } & \multicolumn{2}{c}{ Suction } \\
Events & Total & Events & Total \\
123 & 156 & 19 & 80 \\
97 & 186 & 130 & 181 \\
53 & 56 & 54 & 56 \\
22 & 31 & 44 & 71 \\
42 & 47 & 31 & 51 \\
81 & 100 & 84 & 100 \\
20 & 29 & 19 & 27 \\
24 & 34 & 99 & 115 \\
46 & 48 & 48 & 48 \\
37 & 61 & 28 & 60 \\
49 & 92 & 46 & 92 \\
36 & 50 & 30 & 50 \\
14 & 44 & 13 & 44 \\
& & & \\
& 934 & & 975
\end{tabular}

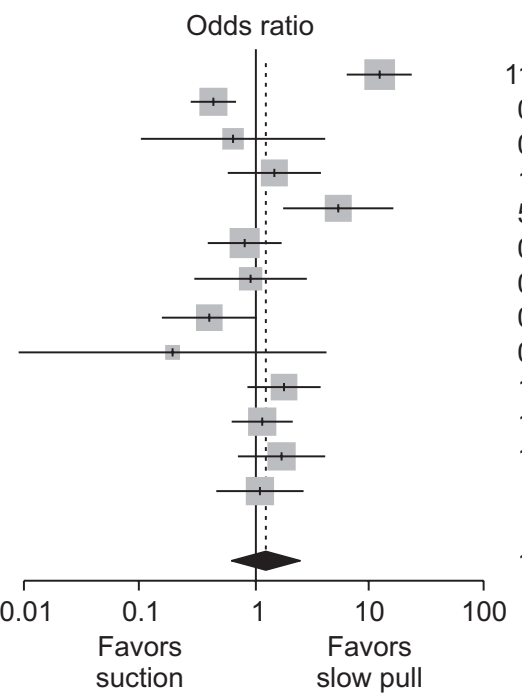

OR

$95 \% \mathrm{Cl}$

$11.97 \quad[6.29 ; 22.75]$

$0.43 \quad[0.28 ; 0.66]$

$0.65 \quad[0.11 ; 4.07]$

$1.50 \quad[0.60 ; 3.73]$

$5.42 \quad[1.83 ; 16.03]$

$0.81 \quad[0.39 ; 1.69]$

$0.94 \quad[0.30 ; 2.93]$

$0.39 \quad[0.16 ; 0.96]$

$0.19 \quad[0.01 ; 4.10]$

$1.76 \quad[0.86 ; 3.63]$

$1.14 \quad[0.64 ; 2.03]$

$1.71 \quad[0.74 ; 3.96]$

$1.11 \quad[0.45 ; 2.76]$

1.28

[0.68; 2.40]

$p=0.45$
Weight

$8.8 \%$

$9.3 \%$

$5.3 \%$

$8.1 \%$

$7.5 \%$

$8.6 \%$

$7.4 \%$

$8.1 \%$

$3.0 \%$

$8.6 \%$

$9.0 \%$

$8.3 \%$

$8.1 \%$

$100.0 \%$

Fig. 4. Comparison of specimen quality between slow pull and conventional suction techniques. (A) Blood contamination (overall). (B) Cellularity. The odds ratio (OR) (center of the gray square) for slow pull compared with conventional suction techniques is presented for each study along with its $95 \%$ confidence interval ( $\mathrm{Cl}$; horizontal line). The summary OR based on the meta-analysis is presented at the bottom of each panel (black diamond) along with its $95 \% \mathrm{Cl}$ (upper and lower limits). The $\mathrm{p}$-value for the $\mathrm{Q}$-statistic for between-study heterogeneity is shown. 
$(\mathrm{p}=0.48)$. Meanwhile, when FNB needles were used, ORs of accuracy, sensitivity, blood contamination and cellularity were $1.49(\mathrm{p}=0.40), 1.17(\mathrm{p}=0.84), 0.65(\mathrm{p}=0.17)$ and $2.59(\mathrm{p}=0.10)$, suggesting SP technique provided more cellularity in specimens obtained by FNB needles, compared to CS technique. The subgroup analysis of studies including pancreatic lesions alone revealed that ORs of accuracy, sensitivity, blood contamination and cellularity were 1.54 $(\mathrm{p}=0.04), 1.51(\mathrm{p}=0.16), 0.56(\mathrm{p}<0.01)$ and $1.19(\mathrm{p}=0.51)$.

\section{DISCUSSION}

SP technique was originally reported to reduce the amount of blood contamination in tissue specimens obtained via EUS-FNA and thereby increase the diagnostic yield of pancreatic masses. ${ }^{37}$ However, an experimental study failed to demonstrate differences in the suction force between SP technique and no suction. ${ }^{38}$ Furthermore, there are some factors that may affect outcomes of EUSguided tissue acquisition other than suction such as the needle size and the needle type. Since the first report of SP technique, ${ }^{37}$ there have been a few studies comparing SP and CS with conflicting results. In this meta-analysis of SP and CS for EUS-guided tissue acquisition, the accuracy of SP tended to be higher with significantly less blood contamination. Furthermore, in the analysis of four RCTs, SP was associated with approximately 2-fold higher likelihood of accurate pathological diagnosis compared to CS. Meanwhile, the sensitivity of SP tended to be high but the tendency was less prominent in the analysis of four RCTs.

Our previous study suggested that SP might provide better diagnostic yield when a 25-gauge FNA needle was used. In this meta-analysis, we conducted subgroup analyses by the needle size. ORs of accuracy and sensitivity comparing SP to CS appeared higher in 25-gauge needles than those in 22-gauge needles (Table 3). However, as revealed by the wide range of the corresponding $95 \% \mathrm{CI}$, the number of studies included in the subgroup analysis of a 25-gauge needle was limited and it is difficult to draw a solid conclusion.

In an experimental study using FNB needles, ${ }^{39}$ the amounts of tissue obtained by no suction, SP and CS were significantly different, while another bench-top experimental study using FNA needles did not reveal significant differences in the suction force between no suction and $\mathrm{SP}^{38}$ In our meta-analysis of clinical studies, SP seems to work both in FNA and FNB needles with similar ORs of accuracy and sensitivity but SP was likely to provide better cellularity when combined with FNB needles. However, the definition of cellularity among studies, especially between
FNA and FNB needles, might differ and the results need to be interpreted with caution. Meanwhile, there has been increasing interest in genome profiling for precision medicine and EUS-FNB is expected to provide better samples for genome profiling. ${ }^{6}$ Thus, the best suction technique to obtain tissue adequate for genome profiling during EUSFNB should be further explored.

Less blood contamination in SP seems consistent across all the subgroups examined but there were no significant differences in cellularity between SP and CS. This discrepancy might be due to the various definitions of this outcome variable in the included studies. While most studies evaluated blood contamination based on semiquantitative analyses with 3 to 4 degrees, cellularity was evaluated both by semiquantitative analyses and by the presence of core. To allow inter-study integration or comparison, we need standardization of reporting systems for EUS-guided tissue acquisition so that these scores represent a good correlation with the diagnostic yield.

The inclusion of various studies is the strength of our meta-analysis, but there are some limitations. First of all, while accuracy and sensitivity are robust outcomes, there are no standard criteria for definitions of blood contamination and cellularity as described above. Furthermore, definition of malignancy was not necessarily described in some papers and might differ among studies. Heterogeneity of these criteria for outcomes can affect the results of our meta-analysis. In addition, the amount of suction differs from 5- to 20-mL in the CS group. During EUS-FNA using a 25-gauge needle, high negative pressure of $50-\mathrm{mL}$ suction was associated with more suitable tissue specimens for pathological examinations. ${ }^{40}$ There is no RCT comparing different amounts of CS between 5- to 20-mL but clinical outcomes might differ by suction techniques. Our meta-analysis focused on the suction technique but a variety of factors, such as the size and type of needles as well as target lesions, can affect clinical outcomes. Thus, interpretation of our meta-analysis should be interpreted with caution.

In conclusion, SP provided significantly less blood contamination but the superiority of accuracy and sensitivity did not reach statistical significance in our meta-analysis. In subgroup analyses, SP showed better accuracy in RCTs, 25-gauge needles and pancreatic lesions.

\section{CONFLICTS OF INTEREST}

No potential conflict of interest relevant to this article was reported. 


\section{AUTHOR CONTRIBUTIONS}

Study concept and design: Y.N., T.H. Data acquisition: Y.N., T.H., R.H. Data analysis and interpretation: Y.N., R.H., T.H. Drafting of the manuscript: Y.N., T.H. Critical revision of the manuscript for important intellectual content: Y.N., T.H., R.H., T.S., K.I., K.S., T.S., N.T., S.M., H.K., K.K. Statistical analysis: Y.N., T.H.

\section{ORCID}

Yousuke Nakai https://orcid.org/0000-0001-7411-1385 Tsuyoshi Hamada https://orcid.org/0000-0002-3937-2755 Ryunosuke Hakuta

https://orcid.org/0000-0001-7653-7689

Tatsuya Sato https://orcid.org/0000-0002-5142-4706 Kazunaga Ishigaki https://orcid.org/0000-0001-6773-9465 Kei Saito https://orcid.org/0000-0003-2290-9373 Tomotaka Saito https://orcid.org/0000-0001-6008-1648 Naminatsu Takahara

https://orcid.org/0000-0002-1265-3100

Suguru Mizuno https://orcid.org/0000-0001-7216-2269

Hirofumi Kogure https://orcid.org/0000-0002-2355-7309 Kazuhiko Koike https://orcid.org/0000-0002-9787-1907

\section{REFERENCES}

1. Vilmann P, Jacobsen GK, Henriksen FW, Hancke S. Endoscopic ultrasonography with guided fine needle aspiration biopsy in pancreatic disease. Gastrointest Endosc 1992;38:172-173.

2. Chang KJ, Albers CG, Erickson RA, Butler JA, Wuerker RB, Lin F. Endoscopic ultrasound-guided fine needle aspiration of pancreatic carcinoma. Am J Gastroenterol 1994;89:263266.

3. Hewitt MJ, McPhail MJ, Possamai L, Dhar A, Vlavianos P, Monahan KJ. EUS-guided FNA for diagnosis of solid pancreatic neoplasms: a meta-analysis. Gastrointest Endosc 2012;75:319-331.

4. Varadarajulu S, Fockens P, Hawes RH. Best practices in endoscopic ultrasound-guided fine-needle aspiration. Clin Gastroenterol Hepatol 2012;10:697-703.

5. Bang JY, Kirtane S, Krall K, et al. In memoriam: fine-needle aspiration, birth. Fine-needle biopsy: the changing trend in endoscopic ultrasound-guided tissue acquisition. Dig Endosc 2019;31:197-202.

6. Kandel P, Wallace MB. Recent advancement in EUS-guided fine needle sampling. J Gastroenterol 2019;54:377-387.

7. Wani S. Basic techniques in endoscopic ultrasound-guided fine-needle aspiration: role of a stylet and suction. Endosc Ultrasound 2014;3:17-21.

8. Nakai Y, Isayama $\mathrm{H}$, Chang KJ, et al. Slow pull versus suction in endoscopic ultrasound-guided fine-needle aspiration of pancreatic solid masses. Dig Dis Sci 2014;59:1578-1585.

9. Iwashita T, Nakai Y, Samarasena JB, et al. High single-pass diagnostic yield of a new 25-gauge core biopsy needle for EUS-guided FNA biopsy in solid pancreatic lesions. Gastrointest Endosc 2013;77:909-915.

10. Attam R, Arain MA, Bloechl SJ, et al. "Wet suction technique (WEST)": a novel way to enhance the quality of EUS-FNA aspirate. Results of a prospective, single-blind, randomized, controlled trial using a 22-gauge needle for EUS-FNA of solid lesions. Gastrointest Endosc 2015;81:1401-1407.

11. Gerke H, Rizk MK, Vanderheyden AD, Jensen CS. Randomized study comparing endoscopic ultrasound-guided Trucut biopsy and fine needle aspiration with high suction. Cytopathology 2010;21:44-51.

12. Wani S, Gupta N, Gaddam S, et al. A comparative study of endoscopic ultrasound guided fine needle aspiration with and without a stylet. Dig Dis Sci 2011;56:2409-2414.

13. Higgins JP, Altman DG, Gøtzsche PC, et al. The Cochrane Collaboration's tool for assessing risk of bias in randomised trials. BMJ 2011;343:d5928.

14. Wells GA, Shea B, O'Connell D, et al. The Newcastle-Ottawa Scale (NOS) for assessing the quality of nonrandomised studies in meta-analyses [Internet]. Ottawa: Ottawa Hospital Research Institute; c2000 [cited 2020 Mar 30]. http://www. ohri.ca/programs/clinical_epidemiology/oxford.asp.

15. DerSimonian R, Laird N. Meta-analysis in clinical trials. Control Clin Trials 1986;7:177-188.

16. Higgins JP, Thompson SG. Quantifying heterogeneity in a meta-analysis. Stat Med 2002;21:1539-1558.

17. Paul SR, Donner A. Small sample performance of tests of homogeneity of odds ratios in K 2 x 2 tables. Stat Med 1992;11:159-165.

18. Higgins JP, Thompson SG, Deeks JJ, Altman DG. Measuring inconsistency in meta-analyses. BMJ 2003;327:557-560.

19. Begg CB, Mazumdar M. Operating characteristics of a rank correlation test for publication bias. Biometrics 1994;50:1088-1101.

20. Egger M, Davey Smith G, Schneider M, Minder C. Bias in meta-analysis detected by a simple, graphical test. BMJ 1997;315:629-634.

21. Bansal RK, Choudhary NS, Puri R, et al. Comparison of endoscopic ultrasound-guided fine-needle aspiration by capillary action, suction, and no suction methods: a randomized blinded study. Endosc Int Open 2017;5:E980-E984.

22. Weston BR, Ross WA, Bhutani MS, et al. Prospective randomized comparison of a $22 \mathrm{G}$ core needle using standard versus capillary suction for EUS-guided sampling of solid 
pancreatic masses. Endosc Int Open 2017;5:E505-E512.

23. Lee JM, Lee HS, Hyun JJ, et al. Slow-pull using a fanning technique is more useful than the standard suction technique in EUS-guided fine needle aspiration in pancreatic masses. Gut Liver 2018;12:360-366.

24. Saxena P, El Zein M, Stevens T, et al. Stylet slow-pull versus standard suction for endoscopic ultrasound-guided fineneedle aspiration of solid pancreatic lesions: a multicenter randomized trial. Endoscopy 2018;50:497-504.

25. Lee KY, Cho HD, Hwangbo Y, et al. Efficacy of 3 fine-needle biopsy techniques for suspected pancreatic malignancies in the absence of an on-site cytopathologist. Gastrointest Endosc 2019;89:825-831.

26. Cheng S, Brunaldi VO, Minata MK, et al. Suction versus slow-pull for endoscopic ultrasound-guided fine-needle aspiration of pancreatic tumors: a prospective randomized trial. HPB (Oxford) 2020;22:779-786.

27. Di Mitri R, Mocciaro F, Antonini F, et al. Stylet slow-pull vs. standard suction technique for endoscopic ultrasoundguided fine needle biopsy in pancreatic solid lesions using 20 Gauge Procore $^{\mathrm{TN}}$ needle: a multicenter randomized trial. Dig Liver Dis 2020;52:178-184.

28. Goong HJ, Moon JH, Lee YN, et al. Comparison of slow-pull versus suction technique for histological diagnosis in EUSguided fine needle biopsy of solid pancreatic masses. Gastrointest Endosc 2015;81:AB546.

29. Kin T, Katanuma A, Yane K, et al. Diagnostic ability of EUSFNA for pancreatic solid lesions with conventional 22-gauge needle using the slow pull technique: a prospective study. Scand J Gastroenterol 2015;50:900-907.

30. Yamakita K, Kitano Y, Iwamoto H, et al. A comparative study of suction methods during endoscopic ultrasound-guided fine-needle aspiration (conventional suction versus capillary suction). United European Gastroenterol J 2017;5:A246A247.

31. Bor R, Vasas B, Fábián A, et al. Prospective comparison of slow-pull and standard suction techniques of endoscopic ultrasound-guided fine needle aspiration in the diagnosis of solid pancreatic cancer. BMC Gastroenterol 2019;19:6.

32. Iwashita T, Nakai Y, Samarasena JB, Park DH, Lee JG, Chang
KJ. Endoscopic ultrasound-guided fine needle aspiration and biopsy (EUS-FNAB) using a novel 25-gauge core biopsy needle: optimizing the yield of both cytology and histology. Gastrointest Endosc 2012;75:AB183.

33. Chen JY, Ding QY, Lv Y, et al. Slow-pull and different conventional suction techniques in endoscopic ultrasoundguided fine-needle aspiration of pancreatic solid lesions using 22-gauge needles. World J Gastroenterol 2016;22:87908797.

34. El Haddad R, Barret M, Beuvon F, et al. The slow-pull capillary technique increases the quality of endoscopic ultrasound fine needle biopsy samples in solid pancreatic lesions. Eur J Gastroenterol Hepatol 2016;28:911-916.

35. Wang R, Wang J, Li Y, Duan Y, Wu X, Cheng B. Diagnostic accuracies of endoscopic ultrasound-guided fine-needle aspiration with distinct negative pressure suction techniques in solid lesions: a retrospective study. Oncol Lett 2017;13:37093716.

36. Yang L, Iwai T, Kida M, et al. Analysis of the diagnostic yield of endoscopic ultrasonography-guided fine-needle aspiration in patients with a suspected pancreatic malignancy. Rev Esp Enferm Dig 2018;110:544-550.

37. Chen AM, Park WG, Friedland S, Banerjee S. Endoscopic ultrasound-guided fine needle aspiration versus fine-needle capillary sampling biopsy of pancreatic solid lesions: does technique matter? Gastrointest Endosc 2011;73:AB331.

38. Katanuma A, Itoi T, Baron TH, et al. Bench-top testing of suction forces generated through endoscopic ultrasoundguided aspiration needles. J Hepatobiliary Pancreat Sci 2015;22:379-385.

39. Yamabe A, Irisawa A, Shibukawa G, et al. An experimental study to assess the best maneuver when using a reverse sidebevel histology needle for EUS-guided fine-needle biopsy. Endosc Int Open 2016;4:E56-E61.

40. Kudo T, Kawakami H, Hayashi T, et al. High and low negative pressure suction techniques in EUS-guided fine-needle tissue acquisition by using 25-gauge needles: a multicenter, prospective, randomized, controlled trial. Gastrointest Endosc 2014;80:1030-1037. 